\title{
Pallas Advanced Learning Systems - A research-informed virtual learning kit
}

\section{Introduction}

The concern over gaps between industry requirements of graduate skills and attributes of the current workforce is one of the key public policy challenges (Mourshed, Farrell \& Barton, 2013; World Economic Forum, 2018). High levels of youth unemployment are not uncommon on account of a skills mismatch between job seekers and skill requirements of the industry, thereby bringing into question education design and delivery.

As education institutions recalibrate curricula in light of evolving job roles and skill sets, developing critical and creative thinking, interpersonal and collaborative skills is paramount (World Economic Forum, 2018). Furthermore, the need for developing competencies such as resilience and learning from failure is of particular importance. While curricular re-alignment may be a first step, re-thinking teaching and re-designing learning have equally important roles to play in preparing learners with $21^{\text {st }}$ century skills and competencies.

Historically, many EdTech products have been created embodying attractive user interfaces and superior usability but several still primarily feature transmission of knowledge from instructor to learner. Such transmission of knowledge may be insufficient in preparing learners for the $21^{\text {st }}$ century skills and competencies (Gysi, 2017).

This product review is about a Virtual Learning Kit (VLK) designed by Pallas Advanced Learning Systems, using Learning Sciences research. Learning Sciences is an interdisciplinary field which looks at the pedagogy behind learning and how people learn (Sommerhoff et al., 2018).

\section{Production Description}

PALLAS Advanced Learning Systems (Pallas), is a researchbased EdTech startup in Sydney, Australia. The company was recognized one of Ten to Watch global edtech startup companies (Pallas, n.d.-b). Pallas learning products are designed on Productive Failure (Kapur, 2014) utilising interactive 2D and 3D computer applications for engaging and impactful collaborative learning (Jacobson et al., 2017). These applications serve as supplementary teaching aids to be integrated into the classroom teaching.

Productive Failure (PF) is a learning design strategy, which runs counter to a traditional Direct Instruction methodology. In PF, challenges are designed to create failure as learning through guided failure brings about higher and deeper learning gains (Kapur, 2014). PF learning design is aimed at exposing learners with open-ended, low-structure tasks to induce struggle or even failure, followed by high-structured experiences such as direct instruction by a teacher, worksheets or scaffolds built by intelligent agents inside collaborative virtual worlds (Jacobson et al., 2011).

Pallas 2D and 3D virtual worlds are designed and applied to the promotion of playful investigations as opposed to teaching scientific concepts and methods. The Virtual Learning Kit (VLK) replaces early Direct Instruction with real world challenges which require learners to offer potential solutions by activating their intuitive experiences, informal knowledge, and reasoning. Through data collection, observations, inferences, analysis and report writing, all of which are at the core of a STEM programme, students learn the ways of scientific inquiry as they investigate simulated phenomena, versus being taught. Students are immersed as scientists into virtual worlds which mirror real-world, gaining perspectives and forming habits which are unlikely in most science courses for initial learning of concepts.

\section{Specifications}

According to the Pallas product brochure (Pallas, n.d.-b), the 3D virtual world is a game-like virtual system compatible with both Windows and Mac, designed to create interactive experiences for individuals or small groups. The 2D computer model is powered by NetLogo, a scientifically accurate computer modelling application (Welinsky, 1999). 


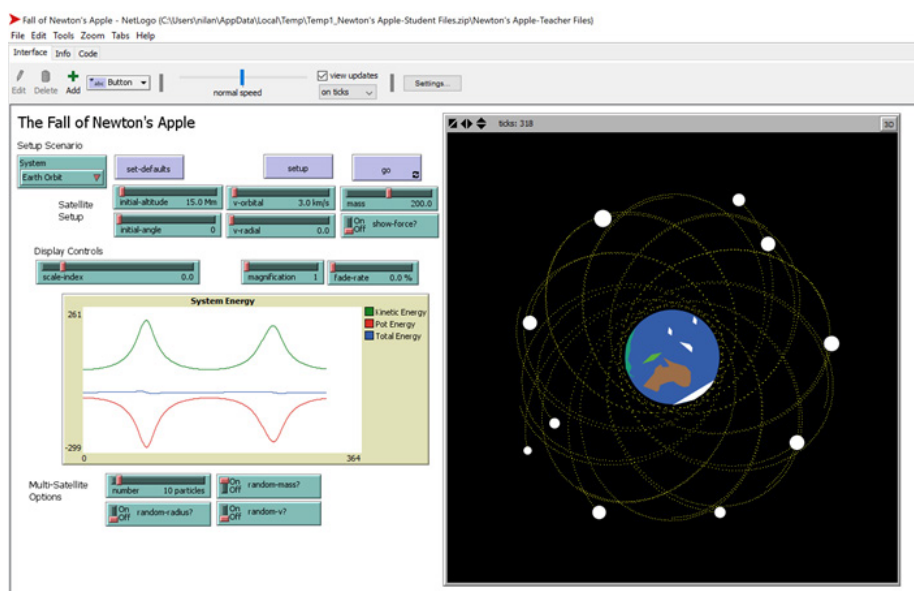

Figure 1: Screenshot of the Pallas 'Fall of Newton's Apple - Physics Virtual Learning Kit' depicting gravitational attraction between satellites. Retrieved February 2018.

Figure 1 above shows a screenshot of the Pallas 2D computer model. Guided by local and regional science standards, these models are similar to systems used by real scientists, enabling visualization of scientific phenomena based on quantitative data and information.

These products are created and validated by discipline experts, working in collaboration with learning science researchers. Furthermore, comprehensive student and teacher guides help participants navigate through the PF learning scenarios step-by-step guidance in implementing $\mathrm{PF}$ in the classroom. The teacher's guide incorporates flexible lesson plans, interactive professional development videos, whilst the learner's guide encompasses challenge problems, directions for using the software as well as scaffolds to maximise learning.

\section{Test Drive}

At first blush, the Pallas website might appear less glamorous compared with other popular EdTech websites. The unique selling point which stood out was the underlying methodology i.e. learning from failure, Productive Failure.

Upon further exploration, it was observed that the VLK immersed the learners in solving real world problems using a system thinking approach. In this process of investigation, learners assumed the role of a scientist and engaged in scientific inquiry, by developing their own research questions, hypothesis, and running experiments to test and analyse their ideas.

In the following paragraphs, reflections stemming from experiencing the VLK as a learner and as a learning designer in an educational setting are shared.

From a learner's perspective, I found the VLK challenging and engaging. The challenge perhaps lies in the fact that there is no teacher instruction at the outset. The learners are immersed into the virtual world, guided by tasks much like games such as Warcraft. Such independence also adds to the engagement as one tends to forget that they are at school, but rather in a game. Elements such as competition, collaboration, strategizing, and improvisation emerge. The visualizations of basic scientific phenomena such as gravity, chemical reactions helped in providing perspective of how such phenomena occur and relate to one another. An example of such a visualization can be seen in figure 2 below. Understanding causal relationships was a lot easier and also intriguing when compared with watching a video or attending a lecture. In addition to the pull factor of the virtual world, there was a strong motivation to continue to be vested in inquiring and reaching the end. It was as if I was on a exploratory journey, tasked with searching for the answers, working with peers and helping each other out when stuck.

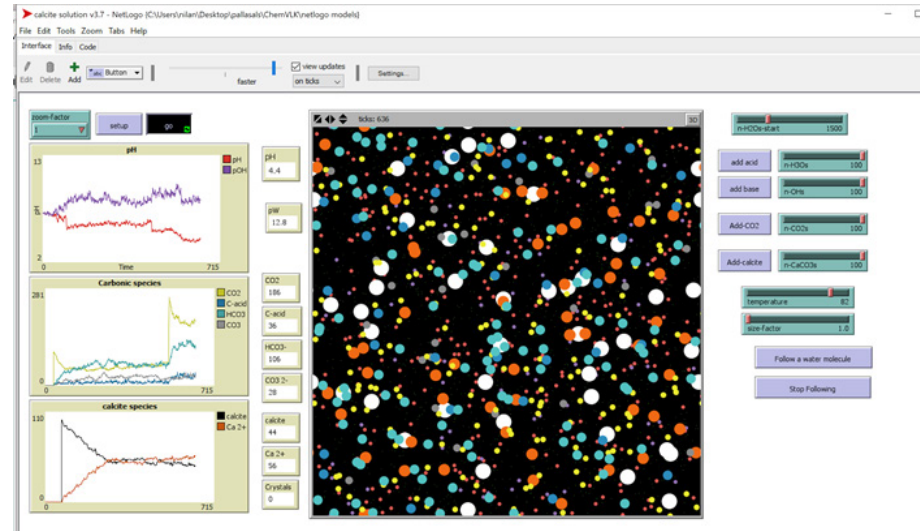

Figure 2: Screenshot of the Pallas 'Carbane Virtual World -- A Chemistry Virtual Learning Kit' depicting the effect of carbon dioxide and high temperature on calcite (white dot) in shelled species.

From a designer's perspective, the experience of designing for the VLK pushed me to move out of my comfort zone as a teacher where I was used to teaching using books and predefined curricula. My primary involvement was with creating a narrative for science scenarios which would then be integrated into a Chemistry VLK. Having content knowledge was essential, however not sufficient, as I found out. Building a narrative required thinking like a storyteller, writing like a playwright and at all times not forgetting that the end goal is to elicit learning through authentic questions which served as yardsticks to explore the virtual world. This is very different from teaching along disciplinary lines, discrete topics from a pre-defined curriculum. In order for the learner to assume the role of a scientist, I as the designer of learning also had to assume the role of a scientist in devising the narrative. Perhaps, the most challenging facet was to ensure that this inquiry aligns with the concept of Productive Failure and calibrating challenging tasks which could only be solved through investigations and collaborations.

Since PF is a deep learning methodology, teaching and designing for it require mindset shifts. The impulse to provide hints in the initial exploratory stage has to be resisted not just in the delivery of the lesson but also in the construction of the narrative. 


\section{Critique and Limitations}

\section{Considerable time and effort in setting up}

While the instructors' time in class might be freed-up to interact and scaffold the learners, the pre-lesson settingup can be substantial especially for instructors new to the methodology. Secondly, deploying the VLK requires several iterations and learning cycles. It is not a short 40-minute, one-off lesson.

Furthermore, in this day and age where there is a high premium placed on products providing 'just in time bitesized' learning, how does this VLK stand in comparison to popular bite-sized learning tools? The VLK is not a plug and play tool as it requires understanding of 'deep learning and Productive Failure' before it can be deployed. This can be time consuming if not taxing. On the learners' side as well, it requires them to completely immerse themselves in the problem before the 'learning' can take place.

\section{Mindset Shift}

Culturally failure is not something which schools and educational systems readily embrace. Thus, it requires buyin from not just management, but other stakeholders such as instructors, students, parents, and maybe even employers. The curriculum too, needs to make space for deeper learning strategies such as 'Productive Failure' before the VLK can be deployed.

\section{Portability}

On the technical side, the VLK has to be downloaded on either a laptop or PC which limits portability to heavy devices compared to smartphones.

\section{Comparision with similar research based}

\section{Collaborative Virtual Worlds (CVW)}

CVWs have been around for more than a decade (Ascilite, 2010; Metcalf, Clarke \& Dede, 2009), one example being ecoMUVE, a middle school CVW developed the Harvard Graduate School of Education, illustrates how the study of ecosystem science concepts through authentic virtual simulations enable deeper scientific inquiry by requiring learners to think about complex causality.

While inquiry-based and apprenticeship-based learning are forms of deeper learning (NMC, 2017), the USP of Pallas lies in the fact that it only scaffolds once learners are unable to complete the task or move ahead. PF and Pallas show results that optimum learning takes place when scaffolds are provided only when learners are unable to solve the task and thus the role of the teacher and the learning environment is paramount, here.

\section{Recommendations}

As higher education institutions look towards immersive and work integrated learning solutions for improved graduate readiness, Pallas may consider collaborating with Higher Education Institutions to explore using cases for this VLK in the HE sector. Secondly, hosting VLKs on the Cloud may increase accessibility and reduce the hardware requirements for storage. This will also allow for the VLK to be deployed across devices, especially smartphones. Lastly, the website may be spruced up to make it visually attractive and an 'on-demand demo' of the VLK might be of relevance in marketing, as well as for garnering feedback.

(The author interned at Pallas from Dec 2017- March 2018, on a purely voluntary basis. Currently the author is not employed nor affiliated to Pallas Advanced Learning Systems in any manner.)

\section{References}

Ascilite. (2010). Scenario-based multi-user virtual environments in education. [Symposium]. Retrieved from http://www.ascilite.org/conferences/sydney 10/procs/ Jacobson-symposium.pdf

Gysi, S. (2017, May 29). Productive failure produces learning outcomes for the 21st century [Blog Post]. Blog on Learning \& Development. Retrieved from https://bold.expert/ productive-failure-produces-learning-outcomes-for-the21st-century/

Jacobson, M. J., Kim, B., Miao, C., Shen, Z., \& Chavez, M. (2010). Design perspectives for learning in virtual worlds. In Designs for learning environments of the future (pp. 111141). Boston, MA: Springer.

Jacobson, M. J., Markauskaite, L., Portolese, A., Kapur, M., Lai, P. K., \& Roberts, G. (2017). Designs for learning about climate change as a complex system. Learning and Instruction, 52, $1-14$.

Jacobson, M. J., Taylor, C., Hu, C., Newstead, A., Wong, W., Richards, D., Taylor, M, Kartiko, I., Porte, J., \& Kapur, M. (2011). Collaborative virtual worlds and productive failure: Design research with multi-disciplinary pedagogical, technical and graphics, and learning research teams. In Computer Supported Collaborative Learning Volume III, Conference proceedings of the 9th International ComputerSupported Collaborative Learning Conference, Hong Kong, China. Retrieved from https://www.isls.org/cscl2011/doc/ CSCL2011ProceedingsVol3.pdf

Kapur, M. (2014). Productive failure in learning math. Cognitive Science, 38(5), 1008-1022. http://doi.org/10.1111/ cogs. 12107

Kirschenbaum, M. (2017, January 4). 10 ways to spot a 
fake news article [Blog post]. The EasyBib Writing Center. Retrieved from http://www.easybib.com/guides/10-waysto-spot-a-fake-news-article/

Metcalf, S. J., Clarke, J., \& Dede, C. (2009). Virtual worlds for education: River City and EcoMUVE. In MiT6 International Conference (pp. 1-6).

Mourshed, M., Farrell, D., \& Barton, D. (2013), Education to employment: Designing a system that works. McKinsey \& Company. Retrieved from https://www.mckinsey.com/ industries/social-sector/our-insights/education-toemployment-designing-a-system-that-works

NMC Horizon Report 2017 : http://cdn.nmc.org/media/2017nmc-horizon-report-he-EN.pdf

Pallas. (n.d.-a). Pallas Advanced Learning Systems. Retrieved from https://pallasals.com/ on 1 Feb, 2018.
Pallas. (n.d.-b). Pallas Product Information Sheet. Retrieved from https://pallasals.com/wp-content/uploads/2017/03/ Pallas-School-Product-Brochure-USA.pdf? on 18 March, 2019.

Sommerhoff, D., Szameitat, A., Vogel, F., Chernikova, O., Loderer, K., \& Fischer, F. (2018). What do we teach when we teach the learning sciences? A document analysis of 75 graduate programs. Journal of the Learning Sciences, 27(2), 319-351.

Wilensky, U. (1999). NetLogo. http://c11cl.northwestern.edu/ netlogo/. Center for Connected Learning and ComputerBased Modeling. Evanston, IL: Northwestern University

World Economic Forum. (2018). The Future of Jobs Report. Retrieved from http://www3.weforum.org/docs/WEF_ Future_of_Jobs_2018.pdf

Copyright: @ 2020 Nilanjana Saxena. This is an open-access article distributed under the terms of the Creative Commons Attribution License (CC BY). The use, distribution or reproduction in other forums is permitted, provided the original author(s) and the copyright owner(s) are credited and that the original publication in this journal is cited, in accordance with accepted academic practice. No use, distribution or reproduction is permitted which does not comply with these terms. 